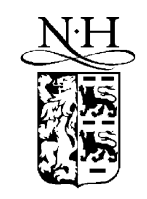

ELSEVIER
Applied Surface Science 178 (2001) 116-126

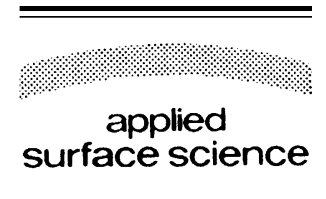

www.elsevier.nl/locate/apsusc

\title{
Effects of additives and chelating agents on electroless copper plating
}

\author{
Yi-Mao Lin, Shi-Chern Yen* \\ Department of Chemical Engineering, National Taiwan University, Taipei 106-17, Taiwan, ROC
}

Received 1 February 2001; accepted 29 March 2001

\begin{abstract}
In this study, ethylenediaminetetraacetic acid (EDTA), triethanolamine (TEA), and ethylenediamine (En) were adopted herein as additives or chelating agents in electroless copper plating, with formaldehyde as the reduction agent. Linear sweep voltammetry was successfully applied to analyze the potential shift of copper complexes and the adsorption capability of chelating agents on a surface. Moreover, the grain size and surface roughness of copper were investigated using atomic force microscopy (AFM). The experimental results for a dual-chelating-agent system indicated that EDTA plays an important role in chelating, while the main effect of TEA is adsorption on copper surfaces to inhibit formaldehyde oxidation. Meanwhile, ethylenediamene is a prominent refining agent owing to its markedly higher adsorption strength on copper surfaces than formaldehyde and TEA. The analyses including linear sweep voltammetry, AFM, and XRD are effective to explore the effect of chelating agents and additives on electroless copper plating and deposits. (C) 2001 Elsevier Science B.V. All rights reserved.
\end{abstract}

Keywords: Electroless copper plating; Additives; Chelating effect; Ethylenediamine; Triethanolamine; Ethylenediaminetetraacetic acid

\section{Introduction}

Electroless plating is a variety of chemical deposition technology, involving the deposition of metals from solutions onto surfaces without applying an external electric voltage $[1,2]$. This method is based on the chemical reduction of metal ions in the solution to metallic atoms on the surface through a reducing agent in the solution, and is not constrained by the shape, size, or conductivity of the supporting substrate. Therefore, electroless plating is a highly effective means of plating metal onto non-conductive substrates. Potential applications for electroless

\footnotetext{
* Corresponding author. Tel.: +886-2-23630397; fax: +886-2-23630397.

E-mail address: scyen@ccms.ntu.edu.tw (S.-C. Yen).
}

plating have recently emerged in IC fabrication and EMI shielding because the electroless metal deposition technique for forming thin metal films does not require vacuums or high temperatures. Extensively used to fabricate printed circuit boards, electroless copper plating is also favored for copper coatings on various non-conductive substrates, such as plastics, glass, and ceramics [3-8]. $\mathrm{Al}_{2} \mathrm{O}_{3}$ and $\mathrm{AlN}$ can be utilized as circuit boards for high performance computers. Meanwhile, TiN is an excellent barrier layer between silicon oxide and metal in ULSI. Finally, $\mathrm{Cu} /$ $\mathrm{Al}_{2} \mathrm{O}_{3}$ is a catalyst in the dehydrogenation of alcohol. Hence, electroless copper plating has received considerable attention owing to the metallization of the above materials [9-12].

Electroless copper plating can be generally described by the following two half-cell reactions [13-15]: 
Anodic reaction

$2 \mathrm{HCHO}+4 \mathrm{OH}^{-} \rightarrow 2 \mathrm{HCOO}^{-}+\mathrm{H}_{2}+2 \mathrm{H}_{2} \mathrm{O}+2 \mathrm{e}^{-}$,

Cathodic reaction

$\mathrm{CuL}_{\mathrm{n}}{ }^{2-n \times m}+2 \mathrm{e}^{-} \rightarrow \mathrm{Cu}+n \mathrm{~L}^{m-}$

where L represents the chelating agent, such as ethylenediaminetetraacetic acid (EDTA), triethanolamine (TEA), or tartaric acid, and $m$ denotes the charge of the chelating agent.

The mechanism of electroless copper plating has been extensively studied [13-19]. Reaction orders have been experimentally measured and empirical rate laws have been proposed $[13,19,20]$. According to the mixed potential theory, it is now widely accepted that electroless plating involves simultaneous cathodic and anodic reactions on the same surface [13,16-18]. Despite the above investigations, many aspects of the electroless plating process remain unexplored. Electroless plating proceeding continuously consumes copper ions, yet chelating agents mostly remain in the bath. Therefore, chelating states with copper ion will gradually change from their initial status. Meanwhile, differing initial concentrations of compositions in the electroless plating bath affect the physical properties of deposits to varying extents. If plating solutions contain only one chelating agent of EDTA at pH 13.5, cupric hydroxide particles precipitate at the bottom of the beaker because of an insufficient concentration of EDTA [21]. Alternatively, if only one chelating agent of TEA exists in the solution, the plating bath is extremely unstable and some autocatalytic reduction copper particles produced in the solutions during electroless copper plating proceeding. The electroless copper deposition reaction would then not only occur on the original surface but also in the solutions. Consequently, a dualchelating-agent system is employed to prevent the above problems.

This investigation examines how various chelating agents or additives affects deposition, such as adsorption effects of additives on the substrate and copper ion interactions with chelating agents in the plating bath, using linear sweep voltammetric method. Additionally, plating rate, resistivity, roughness, grain size, and crystallographic orientation are obtained from the electroless copper plating experiments, thus providing the basis for some predictions and tendencies. Results in this study provide a valuable reference for tuning the ingredients of electroless copper plating recipe for specific applications such as copper metallization of ULSI and EMI shielding.

\section{Experimental}

Electroless plating of non-conducting materials must catalytically activate the substrate surfaces before metals deposit onto themselves. Copper chemical deposition occurs initially on the activated catalytic surfaces and, then, the reduction of copper ions proceeds autocatalytically on the fresh copper surfaces. Hence, the substrates or activators no longer influence electroless copper plating after several atomic layers of copper deposition. Herein, copper sheets were used as substrates for electrochemical measurements.

As indicated previously in Section 1, to avoid cupric hydroxide precipitated and prevent a bath from being unstable as electroless plating was proceeding, the dual-chelating-agent system of EDTA and TEA was adopted to examine our experiments. Consequently, a solution containing $6 \mathrm{~g} / \mathrm{l}$ of $\mathrm{CuSO}_{4} \cdot 5 \mathrm{H}_{2} \mathrm{O}, 14 \mathrm{~g} / \mathrm{l}$ of EDTA, $28 \mathrm{~g} / \mathrm{l}$ of TEA, and $10 \mathrm{ml} / \mathrm{l}$ of $37 \% \mathrm{HCHO}$ for electroless copper plating was used as a reference bath. The concentration of only one species would be changed in the reference bath for each experiment. The $\mathrm{pH}$ of the system was adjusted to 13.5 by $\mathrm{KOH}$. Table 1 lists the various experimental amounts of

Table 1

Experimental array for electroless copper plating (concentration in $\mathrm{g} / \mathrm{l})$

\begin{tabular}{cccc}
\hline Bath & EDTA & TEA & En \\
\hline 1 & 7 & 28 & 0 \\
$2^{\mathrm{a}}$ & 14 & 28 & 0 \\
3 & 21 & 28 & 0 \\
4 & 28 & 28 & 0 \\
5 & 14 & 14 & 0 \\
6 & 14 & 42 & 0 \\
7 & 14 & 56 & 0 \\
8 & 14 & 28 & 0.15 \\
9 & 14 & 28 & 0.30 \\
10 & 14 & 28 & 0.60 \\
\hline
\end{tabular}

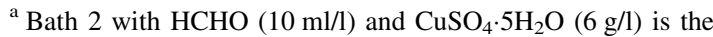
reference bath. 
compositions in the plating bath, and bath 2 is the reference bath. The plating compositions are based on the reference bath except where other is mentioned. The solutions were prepared using analytical grade reagents and double-distilled water. Experiments were performed in a glass beaker placed in a constant temperature bath regulated at $45^{\circ} \mathrm{C}( \pm 0.1)$. All copper sheets were degreased, oxide-removed, and dried with nitrogen.

To measure the resistivity of the copper deposits, electroless copper plating was performed on nonconductive plastic substrates which were catalytically activated in advance. Resistance of the electroless plating layer was measured using a four-point probe driven by a source-measure unit of Keithley 236. The smallest distance between two probes was $1016 \mu \mathrm{m}$ (40 mils) and the probe pressure was $45 \mathrm{~g} / \mathrm{cm}^{2}$.

For linear sweep voltammetry, an $8 \mathrm{~cm}^{2}$ copper sheet was used as the working electrode. A Pt/Ti screen and a commercial electrode of $\mathrm{Ag} / \mathrm{AgCl}$ saturated with $\mathrm{KCl}$ were used as the counter and reference electrodes, respectively. Experiments were conducted in a custom-designed glass cell, which prevented chloride of the reference electrode from diffusing and, then, interacting with copper. The temperature was controlled by circulating thermostatted water $\left(45 \pm 0.1^{\circ} \mathrm{C}\right)$ through the double wall of the above cell. Next, the anodic polarization curves were measured from the formaldehyde-reduced electroless copper bath in the absence of copper ions. Finally, the cathodic polarization curves were measured from the same composition bath without formaldehyde. Linear sweep voltammetry was performed using a potentiostat/galvanostat (EG\&G model 273), and the scan rate was $20 \mathrm{mV} / \mathrm{s}$ for all measurements.

For gravimetric experiments of electroless copper plating, approximately $250 \mathrm{ml}$ of electroless copper bath was used with a $30 \mathrm{~cm}^{2}$ copper sheet. The plating time was 20 min except where other was mentioned. Additionally, the thickness of copper deposition layer and the rates of electroless copper deposition were estimated by the weight gain. Eventually, the resistivity of a deposition layer was obtained.

For orientation and morphology experiments, the structure of the copper deposition film was characterized using an X-ray diffractometer (XRD) (Mac Science M03XHF). The power of the X-ray generator was $3 \mathrm{~kW}$, while the scanning range for XRD was from 30 to $80^{\circ}$. Meanwhile, the sampling width and scanning speed were $0.020^{\circ}$ and $8.000^{\circ} / \mathrm{min}$, respectively. An atomic force microscope (Digital Instruments, Nanoscope IIIa) was employed for surface characterization and roughness measurements, and a NSC15 conical tip with a silicon cantilever (Silicon-MDT Ltd.) was used as the scanning probe. All images were collected in the air using the noncontact tapping mode (scan size: $20 \mu \mathrm{m}$, amplitude: $1.2 \mathrm{~V}$, scan rate: $1.0 \mathrm{~Hz}$ ).

\section{Results and discussion}

\subsection{Linear sweep voltammetry}

Fig. 1 displays the linear sweep voltammetry for formaldehyde oxidation in a $\mathrm{KOH}$ solution at $\mathrm{pH}$ 13.5. The first anodic peak at $-0.4 \mathrm{~V}$ in the absence of formaldehyde (background curve) is attributed to the formation of $\mathrm{Cu}(\mathrm{I})$. The subsequent anodic peak around $0.0 \mathrm{~V}$ results from not only the conversion of $\mathrm{Cu}(\mathrm{I})$ but also some underlying copper metal to the $\mathrm{Cu}(\mathrm{II})$ formed. These above results coincide with those in [22-24]. According to this figure, in the presence of formaldehyde, the first anodic peak occurs at $-0.55 \mathrm{~V}$ mainly owing to the oxidation of formaldehyde. Meanwhile, a lot of hydrogen bubbles were evolved on surfaces of the substrate at the onset of this peak until this peak was over. The anodic peak current density increases with the concentration of formaldehyde, but its increase is limited by the total number of available active sites on the copper surface. At around $-0.15 \mathrm{~V}$, a small prepeak is caused by the oxidation $\mathrm{Cu}(\mathrm{I})$ to $\mathrm{Cu}$ (II). The following anodic peaks for various formaldehyde concentrations evidently indicate that formaldehyde effectively suppresses the formation of $\mathrm{Cu}(\mathrm{II})$ around $0.0 \mathrm{~V}$ [25]. Formaldehyde oxidation proceeds on active sites of the substrate so that formaldehyde must have been previously absorbed on a copper substrate. Consequently, the surface state, e.g. the number of available active sites, will significantly affect the formaldehyde oxidation. The reaction in the first anodic peak is complicated because of involving formaldehyde oxidation, $\mathrm{Cu}(\mathrm{I})$ formation, and their interactions $[22,23,25]$. After peaking, the passivation of the formaldehyde oxidation commences and undergoes the interaction with the 


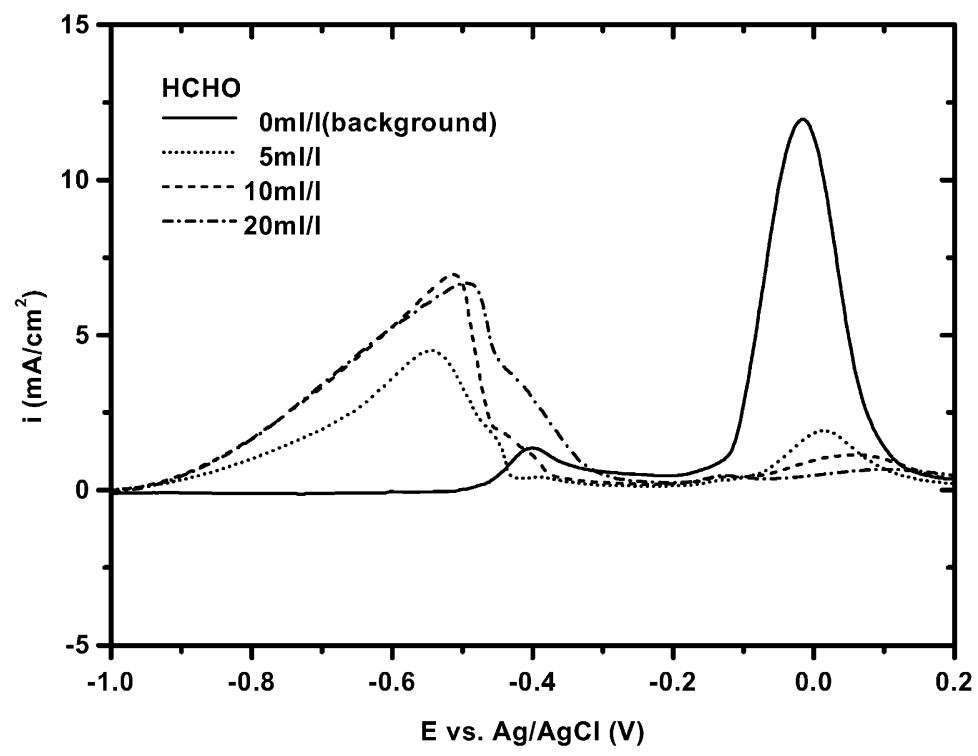

Fig. 1. Linear sweep voltammetric curves for $\mathrm{HCHO}$ oxidation in $\mathrm{KOH}$ at $\mathrm{pH} 13.5$. Initial potential: $-1.0 \mathrm{~V}$; $\mathrm{HCHO}$ : 0, 5, 10, and $20 \mathrm{ml} / \mathrm{l}$.

$\mathrm{Cu}(\mathrm{I})$ formation. Thus, a shoulder in the anodic scan is appeared.

Fig. 2 presents the linear sweep voltammetry for formaldehyde oxidation without copper ion and $\mathrm{Cu}(\mathrm{II})$ reduction without formaldehyde, respectively, in the bath containing TEA and EDTA at $\mathrm{pH}$ 13.5. For anodic scans, the oxidation peak current density of formaldehyde is enhanced around $-0.5 \mathrm{~V}$ due to formaldehyde concentration increase. Meanwhile, its anodic peak current density continues to increase

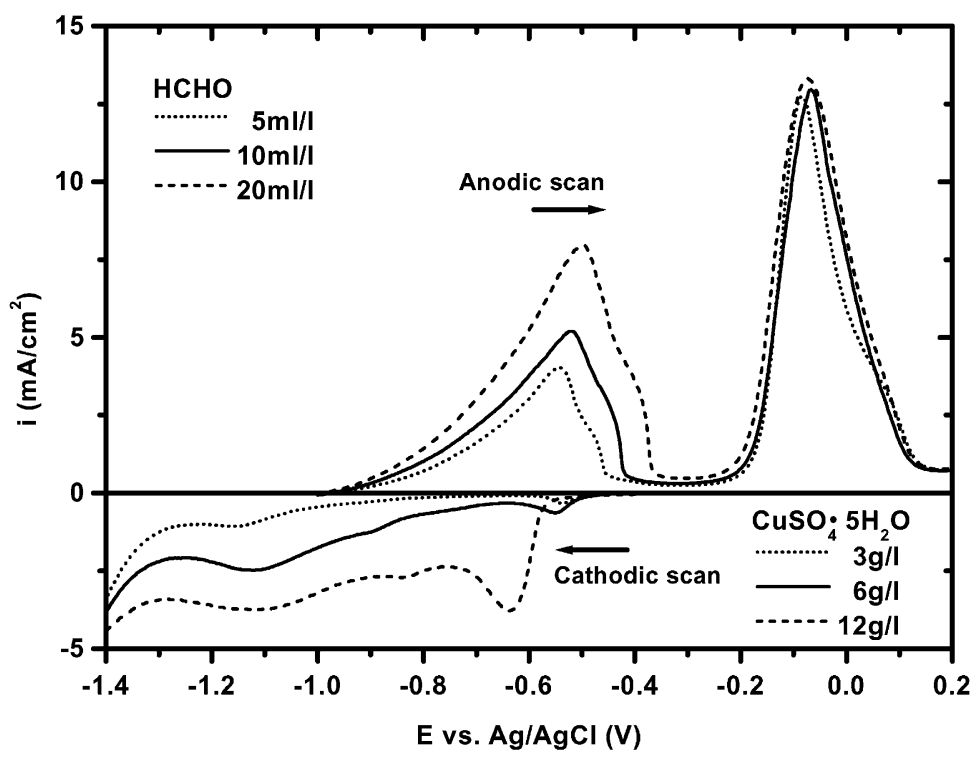

Fig. 2. Linear sweep voltammetry in the reference bath of $14 \mathrm{~g} / \mathrm{l}$ EDTA and $28 \mathrm{~g} / \mathrm{l}$ TEA for HCHO oxidation and Cu(II) reduction, respectively. Anodic scan - HCHO: 5, 10, and $20 \mathrm{ml} / \mathrm{l}$; cathodic scan $-\mathrm{CuSO}_{4} \cdot 5 \mathrm{H}_{2} \mathrm{O}: 3,6$, and $12 \mathrm{~g} / \mathrm{l}$. 
for $20 \mathrm{ml} / \mathrm{l}$ formaldehyde, unlike that in Fig. 1, due to the presence of additives like TEA or EDTA. Furthermore, the anodic peaks of $\mathrm{Cu}$ (II) formation around $0.0 \mathrm{~V}$ are independent of formaldehyde concentration, unlike those in Fig. 1, where the $\mathrm{Cu}$ (II) formation is suppressed by formaldehyde. In addition, the additives of TEA and EDTA restore the $\mathrm{Cu}$ (II) formation at more negative potentials. Fig. 2 also illustrates the effects of cupric ion in the reference bath $(28 \mathrm{~g} / \mathrm{l}$ TEA, $14 \mathrm{~g} / \mathrm{l}$ EDTA, and $\mathrm{pH}$ 13.5) without formaldehyde for cathodic scans of $\mathrm{Cu}(\mathrm{II})$ reduction. The plating bath contains two main species, TEA and EDTA, which are able to chelate cupric ions. The chelating capability of EDTA is much stronger than that of TEA. The chelating effect of each species will be discussed further in subsequent sections. In the case of $12 \mathrm{~g} / \mathrm{l}$ $\mathrm{CuSO}_{4} \cdot 5 \mathrm{H}_{2} \mathrm{O}$ in Fig. 2, the fraction of cupric ions chelated by EDTA is decreased, thereby making its cathodic peak at $-0.65 \mathrm{~V}$ significantly higher than those for 3 and $6 \mathrm{~g} / \mathrm{l} \mathrm{CuSO}_{4} \cdot 5 \mathrm{H}_{2} \mathrm{O}$.

The effects of chelating agents EDTA and TEA are shown in Figs. 3 and 4, respectively. In Fig. 3 the peak current densities of formaldehyde oxidation at $-0.52 \mathrm{~V}$ for various EDTA concentrations are nearly the same, while the peak currents for $\mathrm{Cu}$ (II) formation around $-0.08 \mathrm{~V}$ are enhanced by rising EDTA concentrations. Although not affecting the electrochemical oxidation of formaldehyde, EDTA chelates $\mathrm{Cu}$ (II) so strongly that it increases the peak current densities for $\mathrm{Cu}(\mathrm{II})$ formation. For cathodic scans with increasing EDTA amounts, cupric ion reduction is suppressed more at around $-0.6 \mathrm{~V}$ due to the large formation constant of the $\mathrm{Cu}$ (II)-EDTA complex. For the case of $7 \mathrm{~g} / \mathrm{l}$ EDTA in Fig. 3, the first cathodic scan peak is shifted to about $-0.64 \mathrm{~V}$, this phenomenon is also illustrated in Fig. 2. In Fig. 4, although the formaldehyde oxidation peaks at $-0.52 \mathrm{~V}$ are decreased with increasing TEA concentrations, the heights of the $\mathrm{Cu}$ (II) formation peaks at $-0.08 \mathrm{~V}$ are almost identical. These results indicate that TEA impedes formaldehyde adsorption, and that the chelating capability of TEA is weaker than that of EDTA. The results of cathodic scans shown in Fig. 4 do not clearly differ among these cathodic curves, because most cupric ions are chelated by EDTA. From Figs. 3 and 4 , the first cathodic scan peaks are caused by $\mathrm{Cu}$ (II) reduction of TEA chelating, while the peaks result from that of EDTA chelating appear around $-1.1 \mathrm{~V}$. The potential shifts reflect that $\mathrm{Cu}(\mathrm{II})-\mathrm{EDTA}$ requires more energy than $\mathrm{Cu}(\mathrm{II})-\mathrm{TEA}$ to accomplish $\mathrm{Cu}$ (II) reduction, which is the result of the chelating capability of TEA to EDTA. In other words, the $\mathrm{Cu}$ (II) reduction rate of using TEA as a chelating agent will be higher than that of using EDTA. To summarize, in

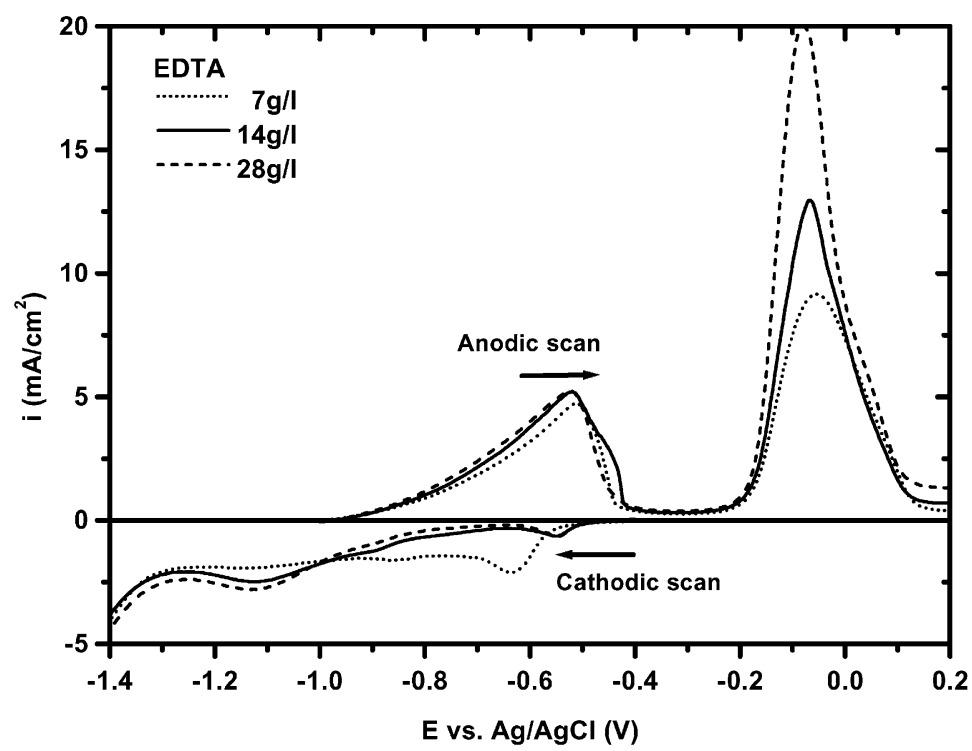

Fig. 3. Effects of EDTA on $\mathrm{HCHO}$ oxidation and $\mathrm{Cu}(\mathrm{II})$ reduction, respectively. EDTA: 7, 14, 28 g/l. 


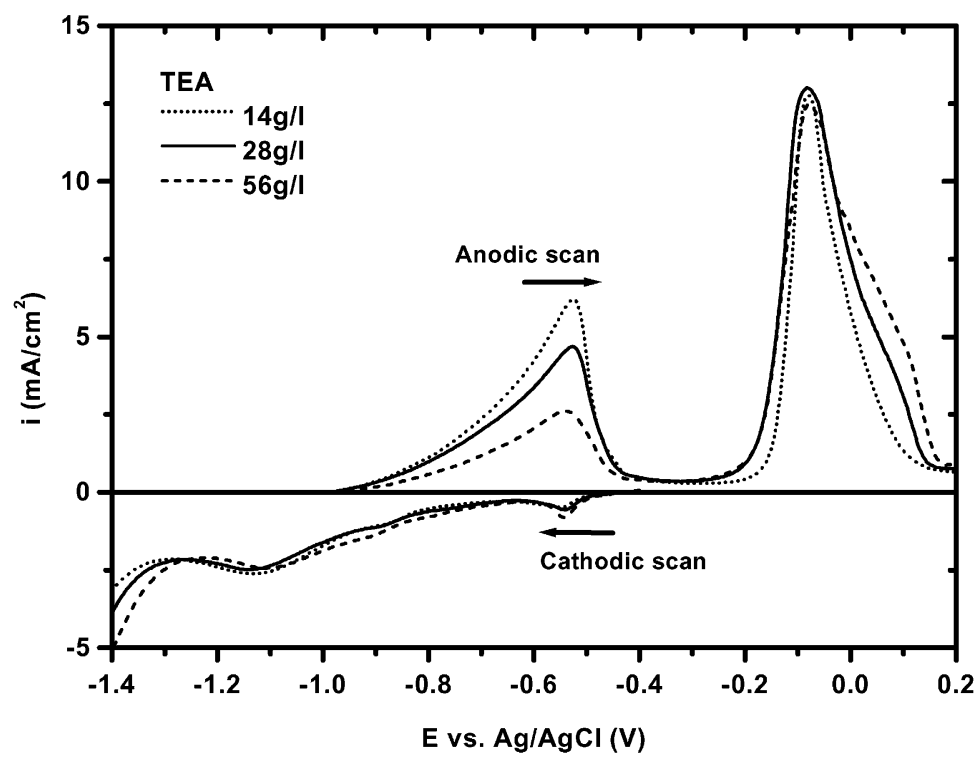

Fig. 4. Effects of TEA on $\mathrm{HCHO}$ oxidation and $\mathrm{Cu}(\mathrm{II})$ reduction, respectively. TEA: 14, 28, and $56 \mathrm{~g} / \mathrm{l}$.

the dual-chelating-agent system, EDTA plays an important role in chelating, while the main effect of TEA is adsorption on copper surfaces, if the solution contains sufficient EDTA. Meanwhile, TEA adsorption inhibits the formaldehyde oxidation on copper surfaces. Otherwise, TEA will take part in chelating obviously.

Fig. 5 displays the effects of ethylenediamine (En) on formaldehyde oxidation and $\mathrm{Cu}(\mathrm{II})$ reduction, respectively. According to the results of anodic scans,

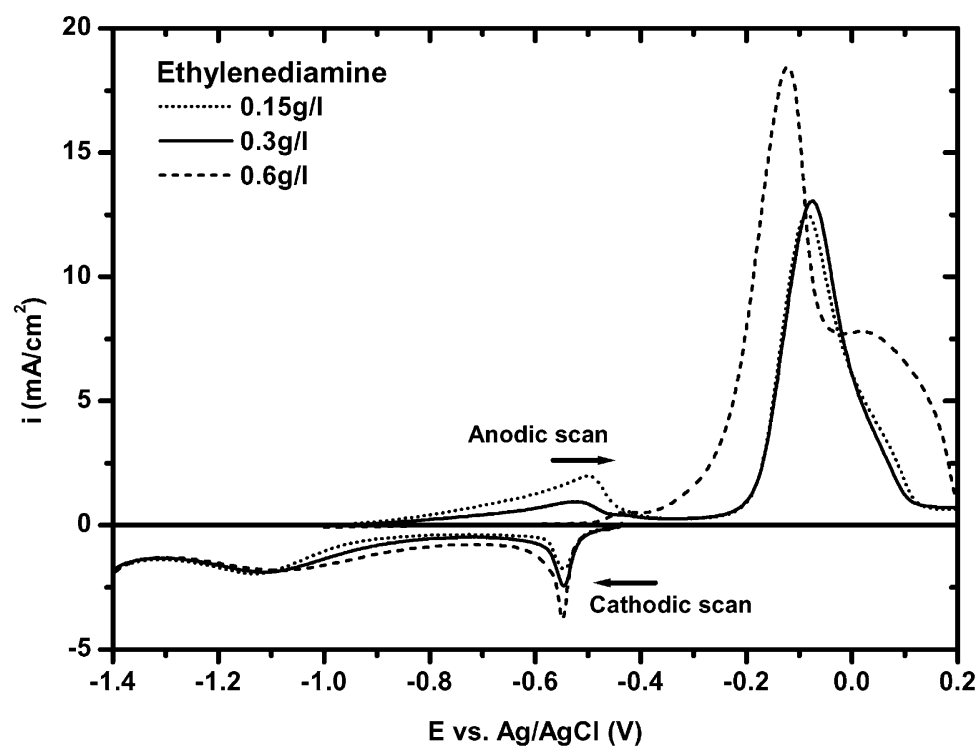

Fig. 5. Effects of ethylenediamine on $\mathrm{HCHO}$ oxidation and $\mathrm{Cu}(\mathrm{II})$ reduction, respectively. Ethylenediamine: $0.15,0.3$, and $0.6 \mathrm{~g} / \mathrm{l}$. 
the adsorption capability of ethylenediamine on copper substrates is stronger than that of TEA and formaldehyde. When a small quantity of ethylenediamine is added in solutions, its adsorption on the copper surface clearly inhibits the electrochemical oxidation of formaldehyde. Thus, the adsorption of ethylenediamine is an obvious negative influence on formaldehyde oxidation. The anodic peaks of 0.15 and $0.3 \mathrm{~g} / \mathrm{l}$ ethylenediamine are similar around $-0.1 \mathrm{~V}$, but $0.6 \mathrm{~g} / \mathrm{l}$ ethylenediamine enhances $\mathrm{Cu}$ (II) formation so that its anodic peak shifts more negatively in potential and has a higher value in current density. The cathodic scans in Fig. 5 illustrate that the peak potentials for $\mathrm{Cu}(\mathrm{II})$ reduction with the addition of ethylenediamine are virtually identical to those with the addition of TEA presented in Fig. 4, but the higher cathodic peak current values indicate that ethylenediamine promotes $\mathrm{Cu}$ (II) reduction.
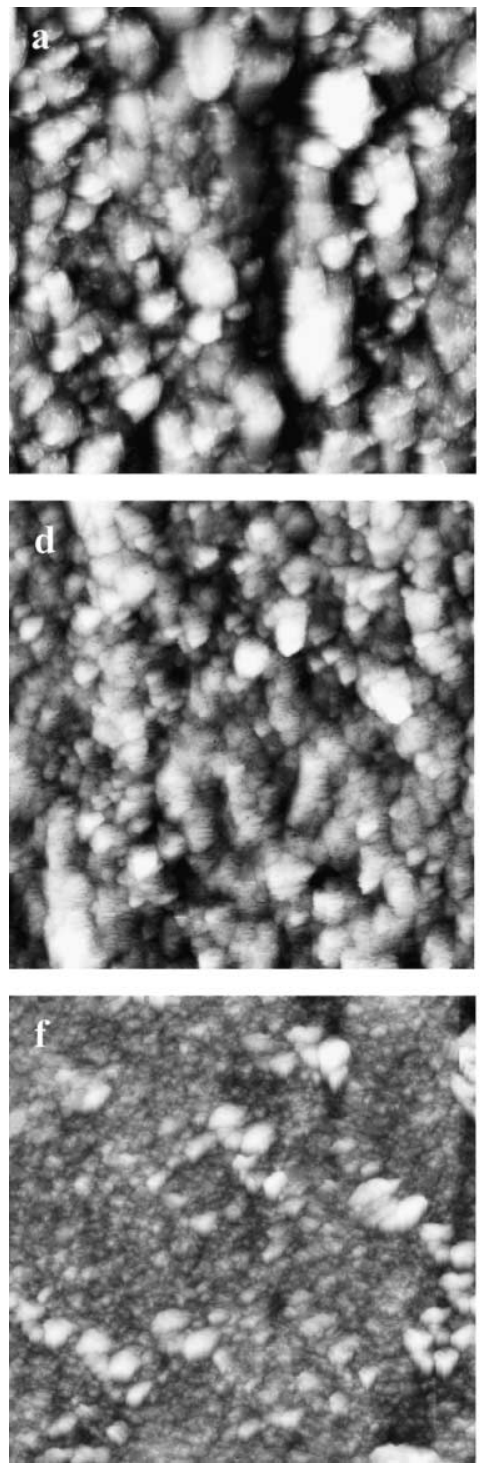
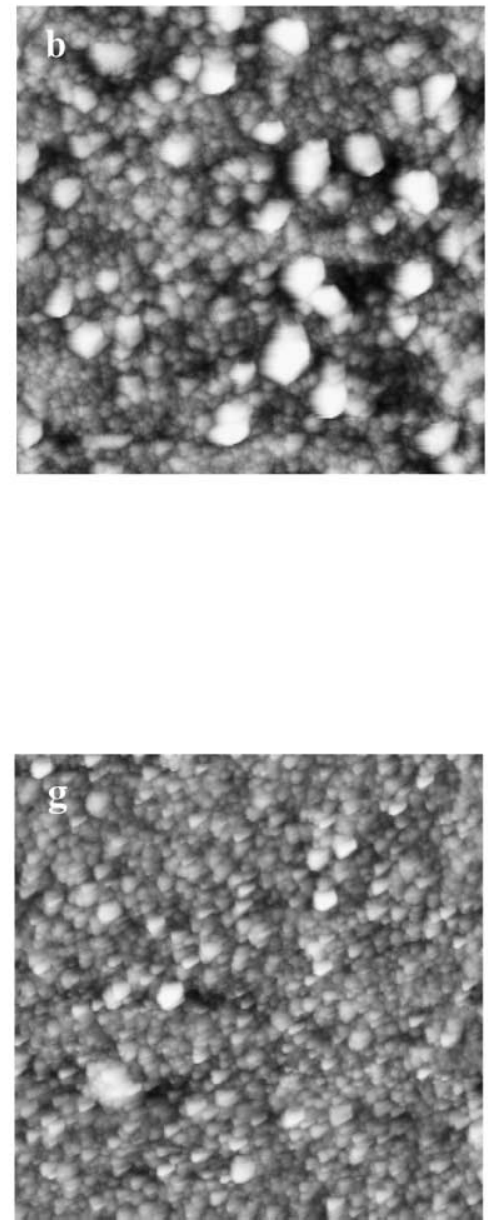
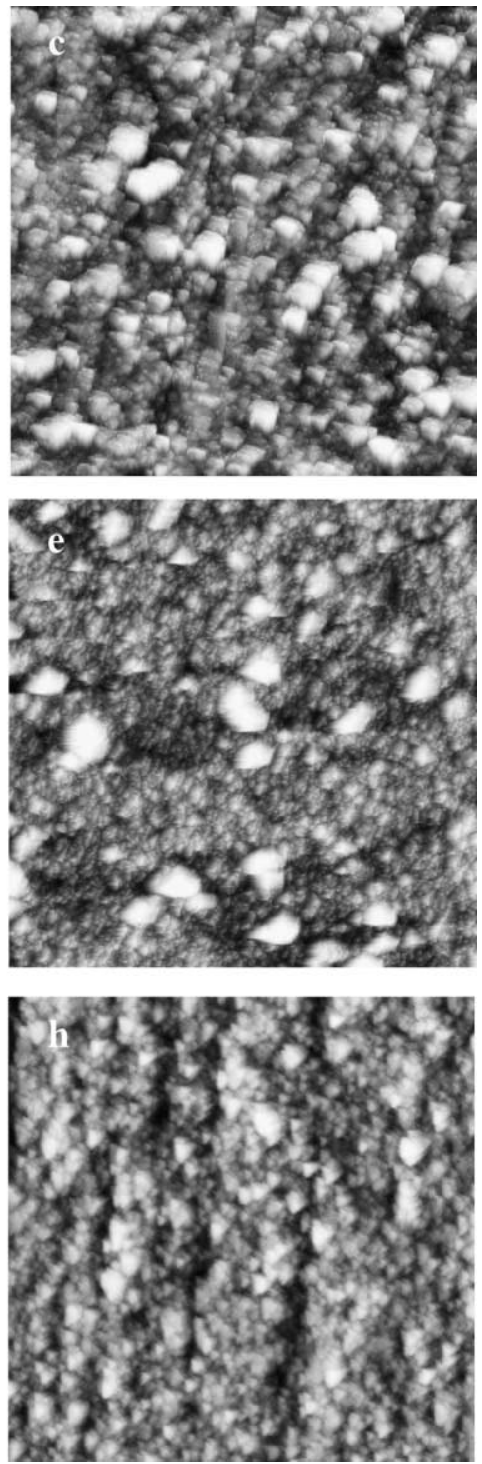

Fig. 6. AFM images of electroless copper plating (HCHO: $10 \mathrm{ml} / 1, \mathrm{CuSO}_{4} \cdot 5 \mathrm{H}_{2} \mathrm{O}: 6 \mathrm{~g} / \mathrm{l}, \mathrm{pH} 13.5$, and temperature: $45^{\circ} \mathrm{C}$ ): (a) bath 1 ; (b) bath 2; (c) bath 4; (d) bath 5; (e) bath 7; (f) bath 8; (g) bath 9; (h) bath 10 . Scan area: $20 \mu \mathrm{m} \times 20 \mu \mathrm{m}$. 
The above studies found that chelating agents and additives influenced the anodic oxidation of formaldehyde and cathodic reduction of $\mathrm{Cu}$ (II) differently. For example, although the potential shift of ethylenediamine complexes was conducive to $\mathrm{Cu}(\mathrm{II})$ reduction proceeding, the strong adsorption of ethylenediamine on a substrate impeded formaldehyde oxidation. In fact, $\mathrm{Cu}(\mathrm{II})$ reduction and formaldehyde oxidation, although occurring simultaneously by themselves, were confirmed to be interdependent. Therefore, the results of Figs. 2-5 provide further insight into the mechanism and phenomena involved in electroless copper plating.

\section{2. $A F M$ and $X R D$ studies}

Fig. 6 displays the AFM image collection of the various compositions in electroless copper plating. The RMS roughness of un-plated surfaces was estimated to be around $21 \mathrm{~nm}$. Fig. $6 \mathrm{~b}$ presents the AFM image of $\mathrm{Cu}$ deposits from the reference bath. Fig. 6a-c illustrate that grain size tends to become more uniform as the concentration of EDTA increased. Their RMS roughness ranges from ca. $166 \mathrm{~nm}$ for $7 \mathrm{~g} / \mathrm{l}$ EDTA (case a) down to ca. $91 \mathrm{~nm}$ for $28 \mathrm{~g} / \mathrm{l}$ EDTA (case c). Meanwhile, Fig. 6b, d, and e indicate that the number of smaller grains increases with the concentration of TEA, but that TEA has a lesser effect on the uniformity of grain size than EDTA does. Their RMS roughness ranges from ca. $108 \mathrm{~nm}$ for $14 \mathrm{~g} / \mathrm{l}$ TEA (case d) down to ca. $71 \mathrm{~nm}$ for $14 \mathrm{~g} / \mathrm{l}$ TEA (case e). Meanwhile, Fig. $6 \mathrm{f}-\mathrm{h}$ show the AFM images of electroless copper plating in the bath with added ethylenediamine. These figures reveal that the grain size of copper deposits decreases and their uniformity improves with an increasing ethylenediamine concentration. Their RMS roughness ranges from ca. $96 \mathrm{~nm}$ for no ethylenediamine (case b) down to ca. $40 \mathrm{~nm}$ for $0.6 \mathrm{~g} / \mathrm{l}$ ethylenediamine (case h). Consequently, ethylenediamine produces excellent results in grain refining owing to its adsorption capability. Fig. 7 summarizes RMS roughness for EDTA, TEA and En. Fig. 8 presents the XRD patterns of electroless copper plating. In the reference bath, the copper nucleation slightly prefers (1 111 1) plane, especially with increased EDTA. However, the addition of ethylenediamine enhances the crystallographic orientation in (2 20$)$ plane.

\subsection{Plating rate and resistivity}

Fig. 9 summarizes the effects of EDTA, TEA, and En on electroless plating rates. The electroless plating

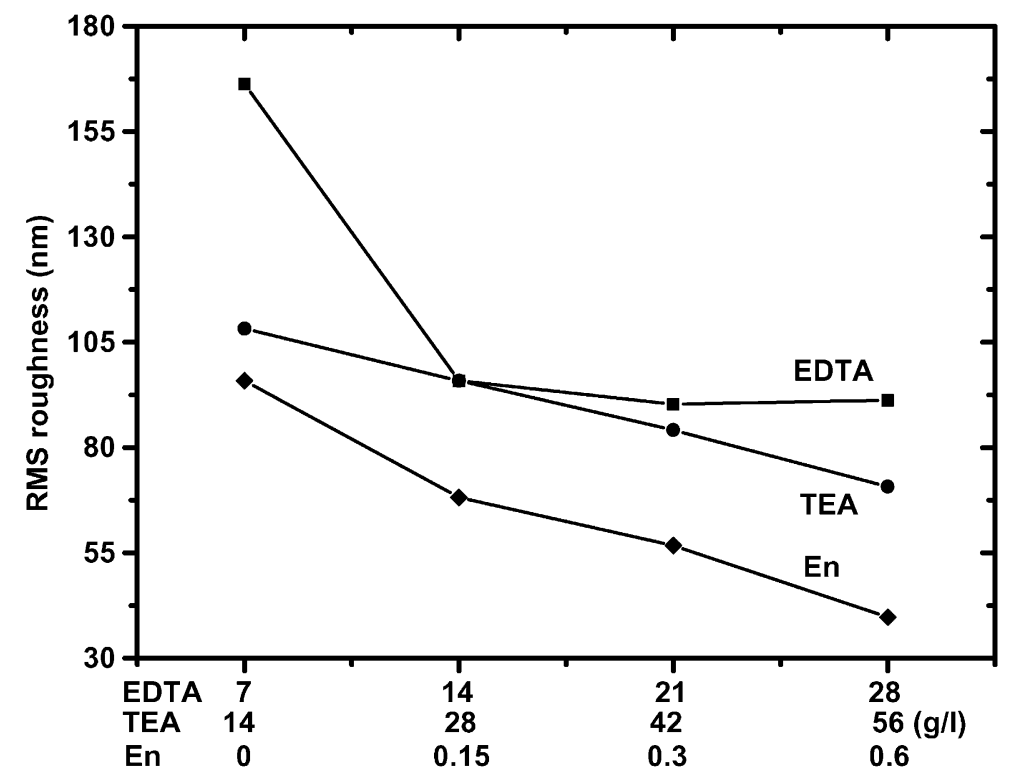

Fig. 7. Dependence of RMS roughness on various concentrations of EDTA, TEA and ethylenediamine (En) in the reference bath. Scan area: $20 \mu \mathrm{m} \times 20 \mu \mathrm{m}$ 


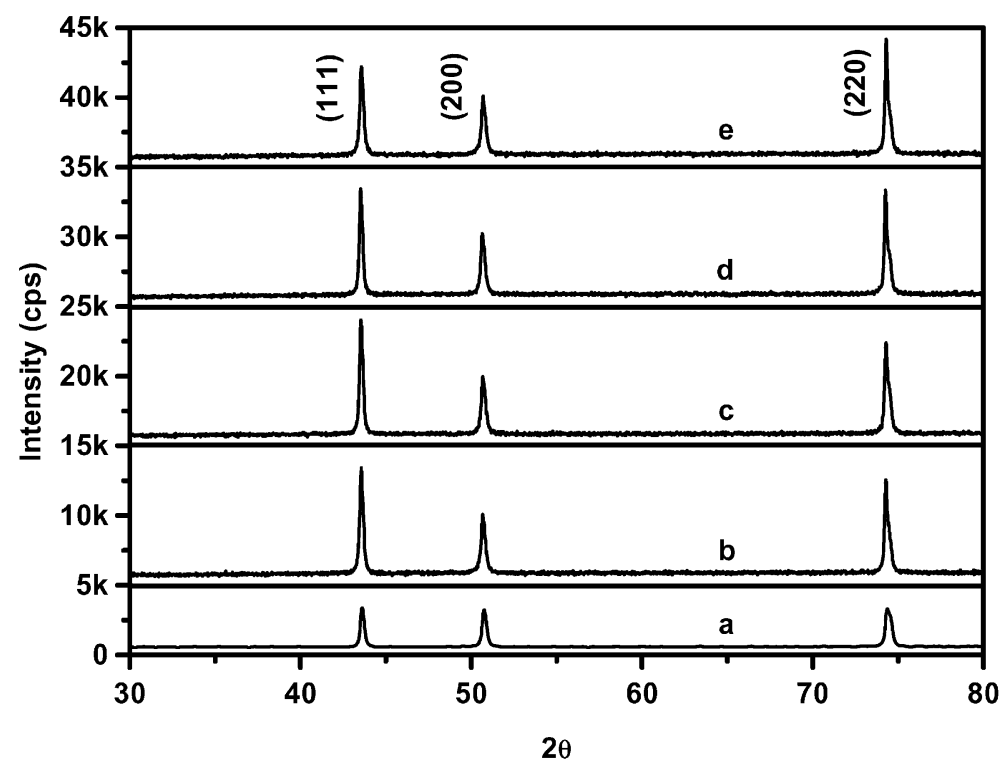

Fig. 8. XRD patterns of electroless copper plating (HCHO: $10 \mathrm{ml} / 1, \mathrm{CuSO}_{4} \cdot 5 \mathrm{H}_{2} \mathrm{O}: 6 \mathrm{~g} / \mathrm{l}, \mathrm{pH}$ 13.5, and temperature: $45^{\circ} \mathrm{C}$ ): (a) un-plated; (b) bath 2; (c) bath 4; (d) bath 7; (e) bath 9 .

rates decrease significantly when increasing the concentration of additives or chelating agents because EDTA, TEA, and En can affect formaldehyde oxidation or $\mathrm{Cu}(\mathrm{II})$ reduction. The plating rate of using TEA as a chelating agent was several times faster than that of using EDTA, which was also reported by several investigators [12,26-28]. Nevertheless, the adsorption character of TEA on copper surface would be

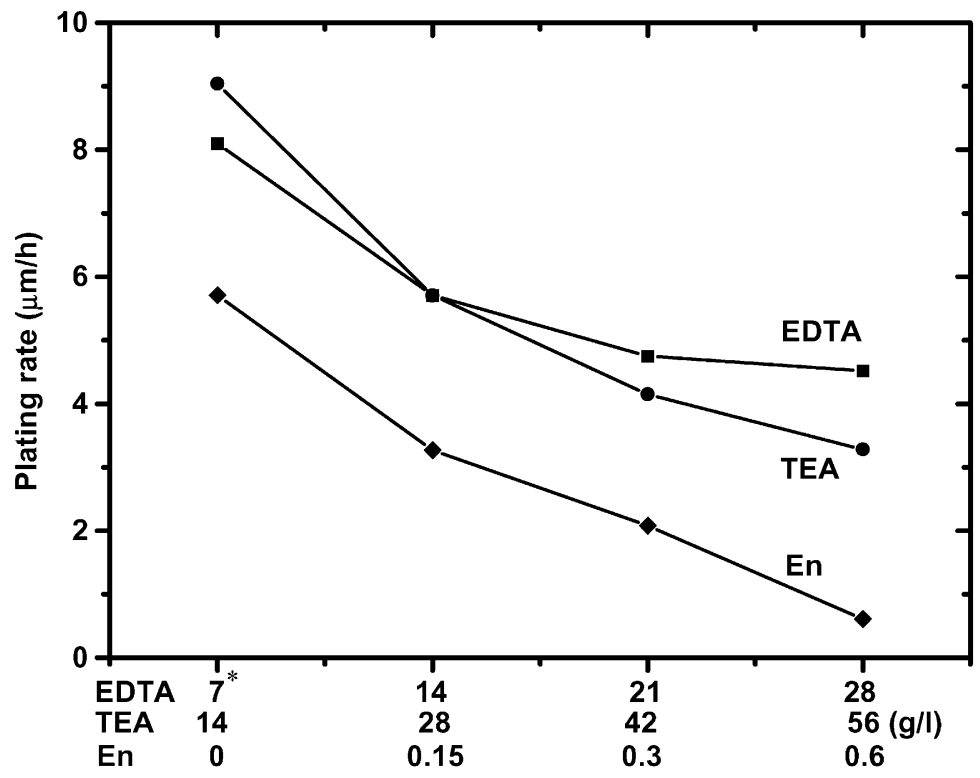

Fig. 9. Dependence of plating rate on various concentrations of EDTA, TEA and ethylenediamine (En) in the reference bath; plating time: $30 \mathrm{~min}$ (' $*$ ' is the precipitation after $25 \mathrm{~min}$ ). 


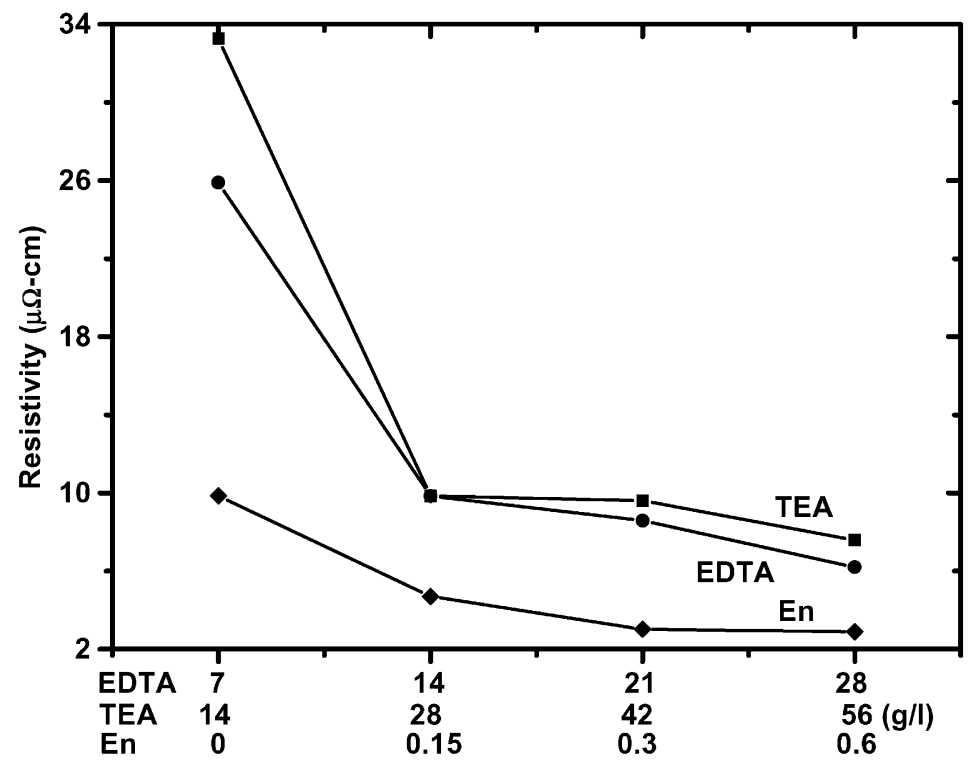

Fig. 10. Resistivity of electroless deposits versus various concentrations of EDTA, TEA and ethylenediamine (En) in the reference bath; plating time: $30 \mathrm{~min}$ excepted $7 \mathrm{~g} / \mathrm{l}$ of EDTA.

obviously appeared with existence of another relatively stronger complexing agent of EDTA in the dualchelating-agent system. Fig. 9 also reveals that the adsorption of additives is a major effect on reducing the plating rate. This phenomenon is especially prominent for ethylenediamine. The plating rate for the reference bath ranges from 5.7 down to $3.3 \mu \mathrm{m} / \mathrm{h}$ as $0.15 \mathrm{~g} / \mathrm{l}$ ethylenediamine is added. In the case of $7 \mathrm{~g} / \mathrm{l}$ EDTA (bath 1), the plating solution converted to be unstable and the copper reduction was greatly vigorous after $25 \mathrm{~min}$, and then the precipitations were produced in solutions due to insufficient EDTA. Hence, the experimental plating rate of bath 1 was measured at $20 \mathrm{~min}$. According to the voltammetric results in the Section 3.1, the plating rate of $7 \mathrm{~g} / \mathrm{l}$ EDTA would be the fastest if this plating bath can be kept stable. The resistivities of electroless copper deposit films were also measured for various concentrations of EDTA, TEA, and ethylenediamine. Fig. 10 summarizes those results. This figure clearly indicates that resistivity increases dramatically when the concentrations of EDTA and TEA are less than those in the reference bath. This same figure reveals that ethylenediamine significantly improves the conductivity of the electroless deposits even if its concentration is only $0.15 \mathrm{~g} / \mathrm{l}$. To summarize, the contribution of ethylenediamine adsorption exceeds its chelating capability in a dual-chelating-agent system. Roughness, grain size, and crystallographic orientation influence resistivity. Generally, additive adsorption appears to significantly reduce the resistivity of electroless deposits.

\section{Conclusion}

This study investigated potential shift distributions of $\mathrm{Cu}$ (II) formation and the additive effects on formaldehyde oxidation using linear sweep voltammetry. In anodic scans, the voltammograms provided adsorption effect of additives on formaldehyde oxidation. Meanwhile, in cathodic scans, the voltammograms revealed complexing capability of chelating agents interacting with copper ions. These results provide a good basis for making predictions regarding the tuning composition of the electroless plating bath. Adsorption capability strength on the copper substrate increases for EDTA, formaldehyde, TEA, and ethylenediamine, respectively. Consequently, the addition of ethylenediamine and TEA should reduce formaldehyde adsorption, and also its oxidation on the surface. Among these three chemical agents (EDTA, 
TEA, ethylenediamine), TEA and ethylenediamine enhanced $\mathrm{Cu}$ (II) reduction more than EDTA, but they two also reduced formaldehyde oxidation. Owing to ethylenediamine existing in the reference bath, the crystallographic orientation preference clearly shifted from (llll 111$)$ to $\left(\begin{array}{lll}2 & 2 & 0\end{array}\right)$ copper crystal plane. The lower plating rate implies a smoother topography, and a smaller or uniform grain size would make lower resistivity easier to achieve. The effect of TEA on electroless copper plating was to shrink the grain, while grain size tended to become uniform as the amount of EDTA increased. Ethylenediamine exhibited strong adsorption on the copper surface, and hence, would be an outstanding grain-refining agent.

\section{References}

[1] G.O. Mallory, J.B. Hajdu (Eds.), Electroless Plating: Fundamentals and Applications, American Electroplaters and Surface Finishers Society, Orlando, FL, 1990.

[2] J.B. Hajdu, Plating Surf. Finish. 83 (1996) 29.

[3] E. Groshart, Met. Finish. 70 (1972) 85.

[4] G.V. Elmore, R.F. Hershberger, J. Electrochem. Soc. 121 (1974) 107.

[5] T. Osaka, Y. Tamiya, K. Naito, K. Sakaguchi, J. Surf. Finish. Soc. Jpn. 40 (1989) 835.

[6] S. Sugihara, A. Iwasawa, K. Onose, J. Yamaki, J. Appl. Electrochem. 26 (1996) 63.

[7] H. Yoshiki, V. Alexandruk, K. Hashimoto, A. Fujishima, J. Electrochem. Soc. 141 (1994) L56.

[8] H. Yoshiki, K. Hashimoto, A. Fujishima, J. Electrochem. Soc. 145 (1998) 1430.
[9] V.M. Dubin, Y. Shacham-Diamand, B. Zhao, P.K. Vasudev, C.H. Ting, J. Electrochem. Soc. 144 (1997) 898.

[10] Y. Shacham-Diamand, V.M. Dubin, Microelectron. Eng. 33 (1997) 47.

[11] J.C. Patterson, M. O’Reilly, G.M. Crean, J. Barrett, Microelectron. Eng. 33 (1997) 65.

[12] H.-F. Chang, C.-F. Yang, Ind. Eng. Chem. Res. 36 (1997) 2080.

[13] S.M. El-Raghy, A.A. Abo-Salama, J. Electrochem. Soc. 126 (1979) 171.

[14] M. Paunovic, J. Electrochem. Soc. 132 (1985) 1155.

[15] P. Bindra, J. Roldan, J. Appl. Electrochem. 17 (1987) 1254.

[16] M. Paunovic, D. Vitkavage, J. Electrochem. Soc. 126 (1979) 2282.

[17] I. Ohno, S. Haruyama, Surf. Technol. 13 (1981) 1.

[18] I. Ohno, Mater. Sci. Eng. A146 (1991) 33.

[19] I.J. Yang, J. Electrochem. Soc. 138 (1991) 2086.

[20] A. Molennar, M. Holdrinet, L. Van Beck, Plating 61 (1974) 238.

[21] J. Shu, B.P.A. Grandjean, S. Kaliaguine, Ind. Eng. Chem. Res. 36 (1997) 1632.

[22] P. Bindra, J. Roldan, J. Electrochem. Soc. 132 (1985) 2581.

[23] L.D. Burke, M.J.G. Ahern, T.G. Ryan, J. Electrochem. Soc. 137 (1990) 553.

[24] L.D. Burke, G.M. Brutin, J.A. Collins, Electrochim. Acta 48 (1998) 1467.

[25] L.D. Burke, T.G. Ryan, J. Electrochem. Soc. 137 (1990) 1358.

[26] K. Kondo, J. Ishikawa, O. Takenaka, T. Matsubara, M. Irie, J. Electrochem. Soc. 137 (1990) 1859.

[27] K. Kondo, J. Ishikawa, O. Takenaka, T. Matsubara, M. Irie, J. Electrochem. Soc. 138 (1991) 3629.

[28] K. Kondo, N. Ishida, J. Ishikawa, M. Irie, Bull. Chem. Soc. Jpn. 65 (1992) 1313. 